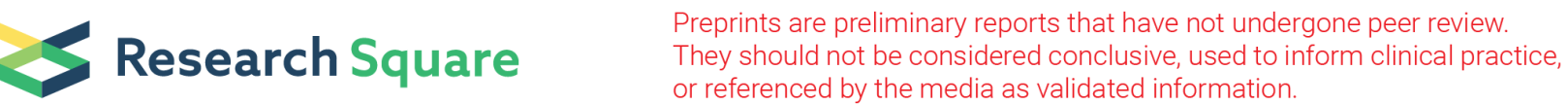

\section{QRT-PCR-based DNA Homologous Recombination Associated 4-Gene Score Predicts Pathologic Complete Response to Platinum-Based Neoadjuvant Chemotherapy in Triple-Negative Breast Cancer}

Ke Zuo

Fudan University Shanghai Cancer Center https://orcid.org/0000-0002-7512-7968

Xiaoying Yuan

Shuwen Biotech Company Ltd

Xizi Liang

Fudan University Shanghai Cancer Center

Xiangjie Sun

Fudan University Shanghai Cancer Center

Shujin Liu

Shuwen Biotech Company Ltd

Philip P. Connell

University of Chicago Department of Radiation and Cellular Oncology

Xingmin Li

Shuwen Biotech Company Ltd

Wentao Yang ( $\square$ yangwt2000@163.com )

Fudan University Shanghai Cancer Center

\section{Research article}

Keywords: -gene score, pCR, homologous recombination deficiency, neo-adjuvant chemotherapy, platinum, TNBC

Posted Date: March 30th, 2021

DOl: https://doi.org/10.21203/rs.3.rs-335000/v1

License: (c) (1) This work is licensed under a Creative Commons Attribution 4.0 International License. Read Full License 


\section{Abstract}

\section{Background}

Cumulative evidences suggested the addition of platinum agents as neoadjuvant chemotherapy (NACT) could improve pathologic complete response (PCR) in triple-negative breast cancers (TNBC). Previous studies showed DNA homologous recombination deficiency (HRD) was a potential biomarker predicting PCR in ER-negative breast cancer. It would be helpful to personalize the use of platinum agents if a predictive biomarker for platinum sensitivity could be developed. Therefore, we tried to develop a HRD gene expression score to predict tumor sensitivity to platinum-based NACT in TNBC.

\section{Methods}

A retrospective cohort of 127 TNBC patients from 2012 to 2017 was included in this study. All of them were diagnosed and received platinum-based NACT in Fudan University Shanghai Cancer Center. Clinical data and pathological data of the patients were collected and reviewed. By using quantitative reverse transcription-polymerase chain reaction (qRT-PCR), the expression level of eight HRD associated genes was analyzed from the formalin-fixed paraffin-embedded core needle biopsy samples which obtained before NACT. A random forest model was built to estimate the weight of each gene expression level and clinical-pathological factors. Samples were randomized into the training set and validation set with different splitting percentage from 50\%:50\% to $90 \%: 10 \%$. The training set was used to modulate parameters and select the best model using 5 -fold cross validation. The performance of the final model was evaluated in the validation set.

\section{Results}

A 4-gene (BRCA1, XRCC5, PARP1, RAD51) expression signature scoring system was developed. TNBC with higher score had nearly quadruple likelihood to achieve $\mathrm{pCR}$ to platinum-based NACT compared with a lower score [odds ratio $(O R)=3.878 ; P<0.001$ ]. At the cut-off value of -2.644 , the 4 -gene score system showed high sensitivity in predicting pCR in breast (93.0\%) and pCR in both breast/axilla (91.8\%), while, at the cut-off value of -1.969 , the 4-gene score showed high specificity for pCR in breast $(85.7 \%)$ and pCR in both breast/axilla (80.8\%). 4-gene score was positively correlated with Ki-67 $\geq 40 \%(P=0.002)$, but negatively correlated with positive lymph nodes counts $(P=0.003)$.

\section{Conclusion}

The qRT-PCR-based 4-gene score can be used as an effective predictor of pCR to platinum-based NACT in TNBC.

\section{Introduction}

Triple-negative breast cancers (TNBC) account for $15 \%-20 \%$ of all breast cancers[1, 2]. This subtype includes a heterogeneous group of BCs lacking expression of both estrogen receptor (ER), progesterone 
receptor (PR), and human epidermal growth factor receptor 2 (HER2). Although the specific target therapies for TNBC are lacking, TNBC often demonstrate sensitivity to cytotoxic neoadjuvant treatment regimens $[3,4]$. Approximately $30-40 \%$ of TNBC patients achieve a pathologic complete response (pCR) with no histological evidence of invasive disease after standard anthracycline plus cyclophosphamideand taxane-based neoadjuvant chemotherapy (NACT)[5].

Cumulative evidences suggested that TNBC are more sensitive to interstrand crosslinking agents that damage DNA such as platinum $[6,7]$. The recent largest meta-analysis included nine randomized controlled trials showed that platinum-based NACT is associated with significant higher pathologic complete response pCR rates compared to platinum-free NACT: PCR rate increased from 37-52.1\%[8]. Nevertheless, available results from single study remained controversial to recommend the use of a platinum agent as standard component for NACT in unselected TNBC patients[8]. Additionally, the longterm outcomes such as overall survival (OS) or disease free survial (DFS) associated with the incorporation of carboplatin are not yet known. Therefore, the newly updated National Comprehensive Cancer Network (NCCN) guideline of breast cancer does not recommend addition of carboplatin to routine neoadjuvant standard chemotherapy for patients with TNBC, but suggests it to be considered in select patients [9].

On this regard, proper biomarkers in predicting sensitivity to platinum agents is needed to better identify the group of TNBC patients, who can benefit from the use of platinum-based NACT. In the early study from Pitroda et. al., a Recombination Proficiency Score (RPS) system could provide prognostic data in individual cancers. The RPS was calculated by the combination of the expression levels of four genes (Rif1, PARI, RAD51, and XRCC5) involved in DNA homologous recombination (HR) repair pathway[10]. The RPS system was initially studied in patients with non-small cell lung carcinomas (NSCLC). Low RPS was associated with poor prognoses in NSCLC, however, it might be negated by chemotherapy because low-RPS tumors are especially sensitive to platinum-based chemotherapy [10]. This validated the ability of RPS to determine sensitivity to platinum-based chemotherapy. Although the predictive effect of RPS was subsequently evaluated in breast cancers, cases involved in the study underwent anthracyclinebased NACT without the inclusion of platinum agent [11]. Thus, it is necessary to carry out further study to elucidate whether similar scoring system can predict efficacy to platinum-based NACT in TNBC.

In our study, we built an algorithm model to correlate the final pCR results with the expression level of HR related genes (RIF1, PARI, RAD51, XRCC5, BRCA1, PARP1, C-Met, and E2F1). Beside the four genes (Rif1, PARI, RAD51, and XRCC5) referred to Pitroda's work, four additional genes (BRCA1, PARP1, C-Met, E2F1) were added in the primary analysis to explore whether these genes also have predictive effect to platinum-based NACT in TNBC. As reported previously, these genes played important role in homologous recombination repair process[2,12-20]. Our final model modified the inclusion of the important genes and the combined 4 gene score showed the ability to predict the sensitivity of platinum-based NACT in TNBC.

\section{Materials And Methods}




\section{Sample selection and data collection}

This study of human TNBC specimens was approved by the institutional review board of Fudan University Shanghai Cancer Center. 129 formalin-fixed paraffin-embedded (FFPE) core needle biopsy samples (before platinum-based NACT) of TNBC patients from 2012-2017 were collected. The detection of HR related genes was conducted by Shuwen (Shuwen Biotech Co., LTD) with blinding clinical information. 127 samples were included in the scoring model building, while 2 samples with less than $20 \%$ tumor contents were excluded. The clinical and pathological data of the patients were collected and reviewed. Tumor-node-metastasis (TNM) stage was evaluated according to the eighth edition of American Joint Committee on Cancer (AJCC) cancer staging system. In our study, the extent of residual disease was assessed using the Miller-Payne (MP) grading system[21]. Pathologic complete response (pCR) in breast/axilla (ypT0/Tis ypN0) was defined as the absence of invasive cancer both in breast and axillary lymph nodes. Pathologic complete response (pCR) in breast (ypT0/Tis) was defined as the absence of residual invasive cancer only in the breast, corresponding to MP grade 5.

\section{Expression Of Target Gene And Reference Gene}

Hematoxylin and eosin (HE) staining was used for one slide of each sample to confirm tumor content above $20 \%$ and used as the reference. RNAs were extracted from macrodissected samples with commercial available RNXtract ${ }^{\circledR}$ RNA Extraction Kit (BioNTech Diagnostics). The extracted RNA content was measured using Qubit ${ }^{\text {tM }} 3$ Fluorometer (Life Technologies) and stored at $-20^{\circ} \mathrm{C}$ until use. Expression of target genes [RAD51, XRCC5, RIF1, PARI, PARP1, BRCA1, C-Met, and E2F1] and a set of 4 reference genes (CALM2, B2M, TBP and GUSB) were detected using TaqMan-based qRT-PCR reactions in 96-well plates, performed with the use of 7500 Real-Time PCR Systems(Applied Biosystems). Cycle threshold (Ct) value of target gene and reference gene were recorded.

\section{Dna Recombination Deficiency Scoring}

Expression of each target gene were normalized using $\mathrm{Ct}$ value of each target gene minus the mean $\mathrm{Ct}$ value of 4 house-keeping genes $(\Delta \mathrm{CtGOI}=\mathrm{CtGOI}-\overline{\mathrm{CtRef}}$ ). . We built random forest (RF) model to estimate the weight of each gene expression level and clinical-pathological factors. Samples were randomized into training set and validation set with deferent splitting percentage from 50\%:50-90\%:10\%. The training set was used to modulate parameters and select the best model using 5 -fold cross validation. The performance of the final model was evaluated in the validation set.

\section{Statistical analysis}

All analyses were performed using R software and SPSS 20.0 (IBM Corp, Armonk, NY, USA). The predictive model training and validating was performed using $\mathrm{R}$ package caret, Classification and 
Regression Training, R package, version 3.6.1.

\section{Results}

The characteristics of 127 eligible patients were listed in Table 1. All of 127 TNBC cases were female patients. The median age at diagnosis was 48 (interquartile range: 41,56 ). All patients received platinumbased chemotherapy. 97/127 (76.4\%) patients underwent modified radical mastectomy, 24/127 (18.9\%) had conservative surgery, and rest patients (6/127) received mastectomy. Most of patients were at early $T$ stage (T1:10.3\%, T2: 66.9\%) and N stage (N0: 25.2, N1: 59.8\%) despite with higher histological grade (Grade 2: 11.8\%, Grade 3: 88.2\%). The patients with MP grade 1 to 5 accounted for $3.9 \%(5 / 127), 15.0 \%$ (19/127), 22.0\% (28/127), 14.2\% (18/127) and 44.9\% (57/127) respectively. The rate of pCR in breast (ypT0/is) in this cohort was $44.9 \%$, corresponding to the rate of MP grade 5 . Compared with the rate of pCR in breast, the rate of pCR in breast/axilla (ypT0/is ypN0) was slightly lower with $38.6 \%$. The median Ki-67 expression level was $70 \%$. There were $78.7 \%$ of cases with $\mathrm{Ki}-67 \geq 40 \%$. 
Table 1

Clinicopathologic features of TNBC patients

\begin{tabular}{|c|c|}
\hline & $\begin{array}{l}\text { Total Patients } \\
(\mathrm{N}=127)\end{array}$ \\
\hline Characteristic & $\mathrm{N}(\%)$ \\
\hline Age (range) & $48(41-56)$ \\
\hline Surgery type & $97(76.4)$ \\
\hline Modified radical mastectomy & $6(4.7)$ \\
\hline Mastectomy & $24(18.9)$ \\
\hline \multicolumn{2}{|l|}{ Conservative surgery } \\
\hline \multicolumn{2}{|l|}{ T stage } \\
\hline 1 & $13(10.3)$ \\
\hline 2 & $85(66.9)$ \\
\hline 3 & $24(18.9)$ \\
\hline 4 & $5(3.9)$ \\
\hline \multicolumn{2}{|l|}{$\mathrm{N}$ stage } \\
\hline 0 & $32(25.2)$ \\
\hline 1 & $76(59.8)$ \\
\hline 2 & $5(3.9)$ \\
\hline 3 & $14(11.0)$ \\
\hline \multicolumn{2}{|l|}{ Histological grade } \\
\hline 1 & $0(0)$ \\
\hline 2 & $15(11.8)$ \\
\hline 3 & $112(88.2)$ \\
\hline \multicolumn{2}{|l|}{ Miller-Payne grade } \\
\hline 1 & $5(3.9)$ \\
\hline 2 & $19(15.0)$ \\
\hline 3 & $28(22.0)$ \\
\hline 4 & $18(14.2)$ \\
\hline
\end{tabular}




\begin{tabular}{|ll}
\hline & \multicolumn{1}{c}{$\begin{array}{c}\text { Total Patients } \\
(\mathbf{N}=127)\end{array}$} \\
\hline 5 & $57(44.9)$ \\
\hline pCR in breast (ypT0/is) & $57(44.9)$ \\
\hline Yes & $70(55.1)$ \\
\hline No & \\
\hline pCR in breast/axilla (ypT0/isN0) & $49(38.6)$ \\
\hline Yes & $78(61.4)$ \\
\hline No & \\
\hline Ki-67 & $100(78.7)$ \\
\hline$\geq 40 \%$ & $27(21.3)$ \\
\hline$<40 \%$ & \\
\hline Abbreviations: T, primary tumor, N, locoregional lymph nodes; pCR, pathological complete response. \\
\hline
\end{tabular}

One-way Analysis of Variance (ANOVA) showed the expression levels of RAD51, XRCC5, PARP1, and BRCA1 were significantly different among distinct MP grade subgroup (all $P<0.05$, Table $S 1$ ). Spearman's rank correlation analysis indicated that expression of RAD51, XRCC5, and BRCA1 were correlated with Miller-Payne grade. (Table S2).

To determine the weight of each gene, we built a random forest (RF) model to estimate the variable importance of each gene. In the RF model, the predictors we started included 8 target gene expression levels, as well as clinical and pathologic factors with age ( $<48 \mathrm{vs} \geq 48)$, T stage, $N$ stage, histological grade, and Ki-67 index (<40\% vs $\geq 40 \%$ ). When samples split into $50 \%: 50 \%$ as training set and validation set, we got the maximized accuracy $(74.6 \%)$, sensitivity $(67.9 \%)$ and specificity $(80.0 \%)$ (Table S3). Variables with importance scores $<70$ (range of 0 to 100) were eliminated, therefore, RAD51, XRCC5, PARP1, and BRCA1 were included in the final RF model. In the final model, the performance at splitting percentage of $70 \%: 30 \%$ was optimal with accuracy of $76.3 \%$ and sensitivity of $76.5 \%$ (Table S4). Then the variable importance scores estimated in the final model was used to calculate the weight of each gene expression level, the sum of each gene weight coefficients equaled to one. Given the inverse relationship of RAD 51 and BRCA1 with MP grade (Table S2), we generated the final 4-gene score algorism: 4-gene score $=-0.242518 * B R C A 1+0.307431 * X R C C 5+0.193327 * P A R P 1-0.256724 * R A D 51$.

According to the final 4-gene score algorism, each sample got a given score. The mean value of 4-gene score is -2.611 with standard variance of 1.287 . The median value of 4 -gene score is -2.242 (interquartile range: $-2.927,-1.736)$. The multiple variable logistic regression analysis demonstrated that 4 -gene score $(\mathrm{OR}=3.878 ; \mathrm{P}<0.001), \mathrm{Ki}-67 \geq 40 \%(\mathrm{OR}=4.569 ; \mathrm{P}=0.028)$ and $\mathrm{N}$ stage $(\mathrm{OR}=2.279 ; \mathrm{P}=0.009)$ are the 
independent predictive factors of $\mathrm{PCR}$ in breast, however, the 4-gene score $(\mathrm{OR}=3.241 ; \mathrm{P}<0.001)$ is the only independent predictive factor of $\mathrm{pCR}$ in breast/axilla (Table 2). Spearman correlation analysis showed 4-gene score is positively correlated with Ki-67 index $(P=0.002)$, but negatively correlated with positive lymph nodes $(P=0.003)$ (Table 3 ).

Table 2

Multiple variable logistic regression analysis for pCR in breast and pCR in breast/axiila

\begin{tabular}{|lllll|}
\hline Variable & pCR in breast & \multicolumn{3}{l|}{ pCR in breast/axilla } \\
\cline { 2 - 5 } & Odds ratio $(95 \% \mathrm{Cl})$ & $\boldsymbol{P}$ & Odds ratio $(95 \% \mathrm{Cl})$ & $\boldsymbol{P}$ \\
\hline 4-gene score & $\mathbf{3 . 8 7 8 ( 2 . 0 2 8 - 7 . 7 4 1 6 )}$ & $<0.001$ & $\mathbf{3 . 2 4 1}(1.744-6.023)$ & $<0.001$ \\
\hline Ki67 $\geq 40 \%$ & $\mathbf{4 . 5 6 9 ( 1 . 1 7 7 - 1 7 . 7 4 0 )}$ & $\mathbf{0 . 0 2 8}$ & $2.628(0.746-9.261)$ & 0.133 \\
\hline T stage & $0.913(0.459-1.818)$ & 0.796 & $1.234(0.652-2.338)$ & 0.519 \\
\hline N stage & $\mathbf{2 . 2 7 9 ( 1 . 2 3 0 - 4 . 2 2 3 )}$ & $\mathbf{0 . 0 0 9}$ & $1.573(0.940-2.630)$ & 0.084 \\
\hline Histological grade & $3.993(0.817-19.526)$ & 0.087 & $2.395(0.532-10.781)$ & 0.255 \\
\hline Age $\geq 48$ & $0.733(0.285-1.890)$ & 0.521 & $0.571(0.232-1.408)$ & 0.224 \\
\hline Abbreviations: T, primary tumor, N, locoregional lymph nodes. & \\
\hline
\end{tabular}

Table 3

Spearman correlation analysis between 4-gene score and clinical-pathological factors

\begin{tabular}{|lll|}
\hline Variable & Coefficience & $\boldsymbol{P}$ \\
\hline T stage & -0.105 & 0.239 \\
\hline N stage & 0.063 & 0.484 \\
\hline Histological grade & 0.085 & 0.345 \\
\hline Ki-67* & 0.277 & 0.002 \\
\hline Positive LN with post-chemotherapy change & -0.296 & 0.001 \\
\hline Positive LN without post-chemotherapy change & -0.073 & 0.421 \\
\hline Positive LN & -0.266 & 0.003 \\
\hline *Ki-67: <40\% vs $\geq 40 \%$. & & \\
\hline Abbreviations: T, primary tumor, N, locoregional lymph nodes; LN, lymph nodes. \\
\hline
\end{tabular}

To investigate the predictive value of the 4-gene score in identifying PCR in breast and PCR in breast/axilla, receiver operating characteristic (ROC) curve analysis was used and yielded an area under the curve (AUC) of 0.816 and 0.782 for pCR in breast and pCR in breast/axilla respectively (Fig. 1). The 
point on the curve that maximized sensitivity (93.0\%: pCR in breast; $91.8 \%$ : pCR in breast/axilla) corresponded to a cut-off value of -2.644 . The optimal cut-off value maximizing specificity $(85.7 \%$ : pCR in breats; $80.8 \%$ : pCR in breast/axilla) on the curve was 1.969 (Table 4). When the cut-off value was set at -2.644 , a negative result might rule out the patients less sensitive to platinum regimen given the low negative likelihood ratios. When the cut-off value of -1.969 is used, a positive result may increase the possibility of the patients to achieve PCR in breast and PCR in breast/axilla by 4.54 and 3.40 folds respectively (Table 4).

Table 4

Performance of 4-gene score in predicting pCR in breast and pCR in breast/axilla

\begin{tabular}{|lllllllll|}
\hline \multicolumn{3}{|c}{ PCR in breast } & \multicolumn{7}{c|}{ pCR in breast/axilla } \\
\hline Cut-off & Sensitivity & Specificity & + LR & - LR & Sensitivity & Specificity & + LR & -LR \\
\hline-2.644 & $93.0 \%$ & $57.1 \%$ & 2.17 & 0.12 & $91.8 \%$ & $51.3 \%$ & 1.88 & 0.16 \\
\hline-1.969 & $64.9 \%$ & $85.7 \%$ & 4.54 & 0.41 & $65.3 \%$ & $80.8 \%$ & 3.40 & 0.43 \\
\hline
\end{tabular}

With the two cut-off values $(-2.644,-1.969)$, the subjects were divided into three subgroups (Table 5). The distributions of $p C R$ in breast $(P<0.001), p C R$ in breast/axilla $(P<0.001)$ and Ki-67 index $(P=0.012)$ were significant different among each group. There was an increasing trend of rates both in $\mathrm{PCR}$ in breast and $\mathrm{pCR}$ in breast/axilla, with higher 4-gene score yielding better response rate. To better illustrate the trend of pCR in breast, the distributions of patients with different Miller-Payne grading in these three subgroups were presented in Fig. 2. Additionally, it is noteworthy that if the 4-gene score higher than $-1.969,91.5 \%$ of the patients showed high Ki-67 index more than $40 \%$. While, if the 4-gene score less than -2.644 , the rate of high $\mathrm{Ki}-67(\geq 40 \%)$ index significant decreased to $65.9 \%$ (Table 5). 
Table 5

The distributions of $\mathrm{pCR}$ rates and $\mathrm{Ki}-67$ index in subgroups divided by 4-gene score.

\begin{tabular}{|c|c|c|c|c|}
\hline Variable & $\begin{array}{l}\text { Score }<-2.644(n= \\
44)\end{array}$ & $\begin{array}{l}-2.644 \leq \text { Score } \\
-1.969 \\
(n=36)\end{array}$ & $\begin{array}{l}\text { Score } \geq \\
-1.969 \\
(n=47)\end{array}$ & $\mathrm{X}^{2} / \mathrm{F}(\mathrm{P})$ \\
\hline pCR in breast & & & & $44.546(<0.001)$ \\
\hline Yes & $4(9.1 \%)$ & $16(44.4 \%)$ & $37(78.7 \%)$ & \\
\hline No & $40(90.9 \%)$ & $20(55.6 \%)$ & $10(21.3 \%)$ & \\
\hline $\begin{array}{l}\text { pCR in } \\
\text { breast/axilla }\end{array}$ & & & & 33.506 \\
\hline Yes & $4(9.1 \%)$ & $13(36.1 \%)$ & $32(68.1 \%)$ & \\
\hline No & $40(90.9 \%)$ & $23(63.9 \%)$ & $15(31.9 \%)$ & \\
\hline Ki-67 & & & & 8.911 \\
\hline$\geq 40 \%$ & $29(65.9)$ & $28(77.8)$ & 43(91.5) & $(0.012)$ \\
\hline$<40 \%$ & $15(34.1)$ & $8(22.2)$ & $4(8.5)$ & \\
\hline
\end{tabular}

\section{Discussion}

Platinum agents (i.e. carboplatin and cisplatin) are cytotoxic DNA damaging agents causing DNA strand breaks and consequent cell apoptosis[12]. This mechanism makes them useful in cancers with DNA HR repair deficiency, especially those harbouring deleterious mutations in the BRCA $1 / 2$ genes[6, 7]. BRCA gene abnormality and TNBC are closely related. Up to $20 \%$ of TNBC patients are carriers of a BRCA germline mutation[22]. Moreover, several other mechanisms involving in the HR pathways have been indicated to platinum response, defining the concept of BRCAness. This genetic signature is defined by epigenetic inactivation of BRCA, mutations in other genes or post-translational modifications of key proteins involved in HR system[23,24]. Since the functions of BRCA1/2 gene and the phenomenon of BRCAness in HR repair mechanism was revealed, several studies attempted to investigate the role of the platinum-based chemotherapy in the neoadjuvant TNBC setting. A series of phase II studies, such as the GEICAM/2006-03, the GeparSixto and the CALGB 40603 trials[25-27], suggested a possible activity and survival benefit of the addition of platinum in the NACT, however, available results are mixed and controversial. According to current breast cancer guidelines, the routine use of platinum agents as part of neoadjuvant therapy for TNBC is not recommended for most patients, however, it may be considered in select patients requiring better local control[9]. Therefore, predictive biomarkers for platinum in BC represent an unmet clinical need. 
Recently, three independent DNA-based measures of genomic instability resulting from HR repair defects were developed. The test was based on genomic alterations with loss of heterozygosity (LOH)[28], telomeric allelic imbalance (TAI)[29] and large-scale state transitions (LST)[30]. The combination of the three scores, called HRD score,could distinguish homologous recombination deficient tumors from nondeficient tumors[31,32]. HRD is defined by a threshold of HRD score equal or over 42 [33, 34]. It has been reported that HRD-high tumors were sensitive to platinum-containing regimens, indicating a clinical utility of HRD score for the selection of patients who were more likely to respond to platinum [34]. However, the BrighTNess study showed that higher $\mathrm{pCR}$ rates was not related to HRD status in the platinum-containing NACT [35]. Additionally, Tutt et al. also found similar response rate to carboplatin between HRD-high and HRD-low tumors in the metastatic settings (TNT trial)[36]. Therefore, it is necessary to carry out further studies to confirm the clinical utility of HRD scores as a predictor for response to platinum-containing regimens.

Genomic alterations detected by NGS technique for HRD status actually reflect the pre-transcriptional events, while gene expression profiling can provide a current transcriptional state of tumor samples, since the quantity of RNA varies dynamically during cellular process. In 2014, Pitroda et. al. developed a recombination proficiency score (RPS) system with gene expression profiling to evaluate HRD status and tumor sensitivity to chemotherapy[10]. The RPS score from Pitroda et. al. is calculated by the expression levels of four genes (Rif1, PARI, RAD51, and XRCC5) involved in DNA repair pathway. Initially, the RPS system was studied in patients with non-small cell lung carcinomas (NSCLC), which showed low-RPS tumors are especially sensitive to platinum-based chemotherapy[10]. This indicated RPS has the potential to determine sensitivity to platinum-based chemotherapy. And in their later study, such RPS was used to evaluate sensitivity of breast cancers to anthracycline-based NACT [11]. Compared with the work of Pitroda et.al., our study focused on the response to platinum-based NACT, not on anthracycline-based NACT. Additionally, the final genes used in our study was obtained from the correlation analysis with the pCR results, while the gene list from Pitroda's study were selected from cell line database on topotecan sensitivity.

In our study, eight target genes (RIF1, PARI, RAD51, XRCC5, BRCA1, PARP1, C-Met, and E2F1) were included in primary analysis. Beside the four genes (Rif1, PARI, RAD51, XRCC5) referred to Pitroda's work, four additional genes (BRCA1, PARP1, C-Met, E2F1) were added as well. As reported previously, these genes played important role in HR repair process. BRCA1 protein was an upstream effector and considered as a permanent factor during the whole process despite of the complex mechanism involved in double-strand break repair pathway[12, 13]. E2F1 was a transcription regulator participating various pathways such as cell cycle, proliferation, apoptosis, development and differentiation[15]. E2F1 accumulation was a response to DNA double strand damage in tumor cells and promotes DNA repair[14]. Compared with RIF1 and PARI, PARP1 not only mediates excision repair in single-strand break but also acted as a sensor of DNA double-strand break involving the control and recruitment of important HR proteins[16]. In addition, TNBC were shown to express PARP1 more frequently than other breast cancer subtypes. And high levels of PARP1 expression in breast cancer correlated with improved response to chemotherapy[2]. Importantly, it has been revealed that active PARP-1 could enhance E2F1 transcription 
factor activity in HR related DNA repair process[17]. Furthermore, several studies showed that C-MET inhibition reduced RAD51 phosphorylation by impairing its nuclear translocation and decreased the formation of the RAD51/BRCA2 complex in DNA damage response[18, 19]. Additionally, C-Met is not only a clinical prognostic marker but also a predictive marker of response to chemotherapy in patients with breast cancer. Interestingly, previous studies have also indicated that c-Met related with and phosphorylated PARP-1 at Tyr907, and inhibiting both c-Met and PARP-1 could synergize to suppress the growth of breast cancer cells [20]. Considering the evidence showed above, these eight genes were put into primary analysis. As a result, the expression level of BCRA1 and PARP1 presented significant correlation with different MP grading subgroups, while RIF1 and PARI didn't. Thus, two genes (RIF1 and PARI) referred in Pitroda's final formula were replaced by BRCA1 and PARP1.

Our study showed that, TNBC with higher score had nearly quadruple likelihood to achieve pCR to platinum-based NACT compared with a lower score. Moreover, a test result below -2.6440 might be used to rule out the patient with less sensitivity to platinum regimen; and a result above -1.9692 might be rule in the patient with increased possibility to achieve PCR. However, if the subset acquired the value between -2.6440 and -1.9692 , the predictive ability of 4-gene score was significant attenuated.

We also showed that high level Ki-67( $\geq 40 \%)$ correlated with pCR in breast in TNBC. As demonstrated in other studies, the definitions of Ki-67 cutoff values differed widely, ranged from $10-61 \%$ in TNBC[37]. In our study, the median $\mathrm{Ki}-67$ index was 70\%. It is consistent with that baseline Ki-67 values for TNBC are much higher than those for luminal tumors[37]. Due to interobserver variations there was always misclassification in assessment of Ki67 when the level of expression of Ki67 lay in grey zone. In the PACS01 study, when Ki-67 expression ranged between $10 \%$ and $25 \%$, there was a risk of misclassification with $37 \%$; while the risk of misclassification was only $11 \%$ with $\mathrm{Ki}-67$ expression either $<10 \%$ or $\geq 25 \%$ [38]. In our study the median $\mathrm{Ki}-67$ index was significant high with $70 \%$, thus it is almost impossible to misclassified the value of Ki-67. However, using such a high threshold to make further analysis was unwise. Several studies suggested using high $\mathrm{Ki}-67(\geq 30 \%)$ proliferative index could identify those patients with significantly higher breast-related events[39, 40]. Thus, we defined Ki-67 as a classification variable at a $40 \%$ threshold. This cutoff value is in line with that reported earlier by another TNBC study from Wei Wang et.al[41]. Additionally, the 4-gene score is positively correlated with Ki-67, indicating that higher 4-gene score represented higher proliferation rate of tumors.

\section{Conclusions}

In summary, the RT-qPCR-based 4-gene score showed its potential in predicting both pCR in breast and $\mathrm{pCR}$ in breast/axilla with platinum-based NACT in TNBC patients. Despite the current prevalent large genomic characterizations of breast cancers[42], which can provide enormous information for a given patient, our 4-gene score analysis gives several practical points as well. Firstly, our study indicates that the expression level of HR related genes is a proper biomarker to identify tumors with an increased likelihood of response to platinum-based neoadjuvant therapy in TNBC patients. Secondly, the 4-gene score analysis can be performed on formalin-fixed paraffin-embedded material from limited core-needle 
biopsy specimens. Thirdly, the methods are based on RT-qPCR technology by quantifying the expression of four HR related genes, which are more convenient and cost-effective than other sequencing based technologies. Nonetheless, our study is a single-centered study and further validation in other centers with increased sample size would be warranted.

\section{Abbreviations}

NACT; neoadjuvant chemotherapy; pCR:pathologic complete response; TNBC:triple-negative breast cancers; HRD:homologous recombination deficiency; qRT-PCR:quantitative reverse transcriptionpolymerase chain reaction; ER:estrogen receptor; PR:progesterone receptor; HER2:human epidermal growth factor receptor 2; OS:overall survival; DFS:disease free survival; NCCN:National Comprehensive Cancer Network:RPS:Recombination Proficiency Score; HR:homologous recombination; FFPE:formalinfixed paraffin-embedded; AJCC:American Joint Committee on Cancer; TNM:Tumor-node-metastasis; HE:Hematoxylin and eosin; RF:random forest; ANOVA:Analysis of Variance; MP:Miller-Payne; ROC:receiver operating characteristic; LOH:loss of heterozygosity; TAl:telomeric allelic imbalance; LST:large-scale state transitions; NSCLC:non-small cell lung carcinomas; +LR, positive likelihood ratio; -LR, negative likelihood ratio

\section{Declarations}

\section{Ethics approval[}

This study of human TNBC specimens was approved by the institutional review board of Fudan University Shanghai Cancer Center.

\section{Consent for publication!}

All authors agreed to this publication.

\section{Availability of data and materials:}

Included in supplementary materials.

\section{Conflicts of interest:}

Ke Zuo, Xizi Liang, Xiangjie Sun, Philip P. Connell and Wentao Yang have no conflicts of interest to declare. Xiaoying Yuan, Shujin Liu and Xingmin Li are Employee of Shuwen Biotech Co. LTD.

\section{Funding:}

Key Science and Technology Project of Zhejiang Province Special Fund from Zhejiang Provincial Department of Science and Technology (2019C04016) 
$\mathrm{KZ}, \mathrm{XYY}$ and XZL collected and analyzed data and drafted the manuscript. XJS and SJL helped with statistical work and interpretation of data. PPC reviewed the work and gave advices for important intellectual content. WTY and XML designed the work and revising the manuscript critically. All authors contributed to the writing of the final version of the manuscript. All authors read and approved the final manuscript.

\section{Acknowledgements:}

We thank Fang Yi from Sichuan Cancer Hospital \& Institute and Jiayuan Li from Sichuan University for statistical analysis cooperation.

\section{References}

1. Silver DP, Richardson AL, Eklund AC, Wang ZC, Szallasi Z, Li Q, Juul N, Leong CO, Calogrias D, Buraimoh A, et al. Efficacy of neoadjuvant Cisplatin in triple-negative breast cancer. J Clin Oncol. 2010;28(7):1145-53.

2. de Ruijter TC, Veeck J, de Hoon JP, van Engeland M, Tjan-Heijnen VC. Characteristics of triplenegative breast cancer. J Cancer Res Clin Oncol. 2011;137(2):183-92.

3. Carey LA, Dees EC, Sawyer L, Gatti L, Moore DT, Collichio F, Ollila DW, Sartor Cl, Graham ML, Perou $\mathrm{CM}$. The triple negative paradox: primary tumor chemosensitivity of breast cancer subtypes. Clin Cancer Res. 2007;13(8):2329-34.

4. Shao Z, Chaudhri S, Guo M, Zhang L, Rea D. Neoadjuvant Chemotherapy in Triple Negative Breast Cancer: An Observational Study. Oncol Res. 2016;23(6):291-302.

5. Liedtke C, Mazouni C, Hess KR, Andre F, Tordai A, Mejia JA, Symmans WF, Gonzalez-Angulo AM, Hennessy $B$, Green $M$, et al. Response to neoadjuvant therapy and long-term survival in patients with triple-negative breast cancer. J Clin Oncol. 2008;26(8):1275-81.

6. Jin J, Zhang W, Ji W, Yang F, Guan X. Predictive biomarkers for triple negative breast cancer treated with platinum-based chemotherapy. Cancer Biol Ther. 2017;18(6):369-78.

7. von Minckwitz G, Schneeweiss A, Loibl S, Salat C, Denkert C, Rezai M, Blohmer JU, Jackisch C, Paepke S, Gerber B, et al. Neoadjuvant carboplatin in patients with triple-negative and HER2-positive early breast cancer (GeparSixto; GBG 66): a randomised phase 2 trial. The Lancet Oncology. 2014;15(7):747-56.

8. Poggio F, Bruzzone M, Ceppi M, Ponde NF, La Valle G, Del Mastro L, de Azambuja E, Lambertini M. Platinum-based neoadjuvant chemotherapy in triple-negative breast cancer: a systematic review and meta-analysis. Ann Oncol. 2018;29(7):1497-508.

9. National Comprehensive Cancer Network. (NCCN) Clinical Practice Guidelines in Oncology. Breast Cancer, Version 1. 2021-January 15, 2021. Available from https://www.nccn.org/professionals/physician_gls/pdf/breast.pdf. 
10. Pitroda SP, Pashtan IM, Logan HL, Budke B, Darga TE, Weichselbaum RR, Connell PP. DNA repair pathway gene expression score correlates with repair proficiency and tumor sensitivity to chemotherapy. Sci Transl Med. 2014;6(229):229ra242.

11. Pitroda SP, Bao R, Andrade J, Weichselbaum RR, Connell PP. Low Recombination Proficiency Score (RPS) Predicts Heightened Sensitivity to DNA-Damaging Chemotherapy in Breast Cancer. Clin Cancer Res. 2017;23(15):4493-500.

12. Deans AJ, West SC. DNA interstrand crosslink repair and cancer. Nat Rev Cancer. 2011;11(7):467-80.

13. Isono M, Niimi A, Oike T, Hagiwara Y, Sato H, Sekine R, Yoshida Y, Isobe SY, Obuse C, Nishi R, et al. BRCA1 Directs the Repair Pathway to Homologous Recombination by Promoting 53BP1 Dephosphorylation. Cell reports. 2017;18(2):520-32.

14. Singh RK, Dagnino L. E2F1 interactions with hHR23A inhibit its degradation and promote DNA repair. Oncotarget. 2016;7(18):26275-92.

15. Müller H, Bracken AP, Vernell R, Moroni MC, Christians F, Grassilli E, Prosperini E, Vigo E, Oliner JD, Helin K. E2Fs regulate the expression of genes involved in differentiation, development, proliferation, and apoptosis. Genes Dev. 2001;15(3):267-85.

16. Ray Chaudhuri A, Nussenzweig A. The multifaceted roles of PARP1 in DNA repair and chromatin remodelling. Nat Rev Mol Cell Biol. 2017;18(10):610-21.

17. Schiewer MJ, Mandigo AC, Gordon N, Huang F, Gaur S, de Leeuw R, Zhao SG, Evans J, Han S, Parsons T, et al: PARP-1 regulates DNA repair factor availability. EMBO molecular medicine 2018, 10(12).

18. Medová M, Aebersold DM, Zimmer Y. MET inhibition in tumor cells by PHA665752 impairs homologous recombination repair of DNA double strand breaks. International journal of cancer. 2012;130(3):728-34.

19. Medová M, Aebersold DM, Zimmer Y. The Molecular Crosstalk between the MET Receptor Tyrosine Kinase and the DNA Damage Response-Biological and Clinical Aspects. Cancers. 2013;6(1):1-27.

20. Irshad S, Ashworth A, Tutt A. Therapeutic potential of PARP inhibitors for metastatic breast cancer. Expert Rev Anticancer Ther. 2011;11(8):1243-51.

21. Ogston KN, Miller ID, Payne S, Hutcheon AW, Sarkar TK, Smith I, Schofield A, Heys SD. A new histological grading system to assess response of breast cancers to primary chemotherapy: prognostic significance and survival. Breast. 2003;12(5):320-7.

22. Foulkes WD, Stefansson IM, Chappuis PO, Bégin LR, Goffin JR, Wong N, Trudel M, Akslen LA. Germline BRCA1 mutations and a basal epithelial phenotype in breast cancer. J Natl Cancer Inst. 2003;95(19):1482-5.

23. Gerratana L, Fanotto V, Pelizzari G, Agostinetto E, Puglisi F. Do platinum salts fit all triple negative breast cancers? Cancer treatment reviews. 2016;48:34-41.

24. Turner N, Tutt A, Ashworth A. Hallmarks of 'BRCAness' in sporadic cancers. Nat Rev Cancer. 2004;4(10):814-9. 
25. Alba E, Chacon JI, Lluch A, Anton A, Estevez L, Cirauqui B, Carrasco E, Calvo L, Segui MA, Ribelles N, et al. A randomized phase II trial of platinum salts in basal-like breast cancer patients in the neoadjuvant setting. Results from the GEICAM/2006-03, multicenter study. Breast Cancer Res Treat. 2012;136(2):487-93.

26. von Minckwitz G, Schneeweiss A, Loibl S, Salat C, Denkert C, Rezai M, Blohmer JU, Jackisch C, Paepke S, Gerber B, et al. Neoadjuvant carboplatin in patients with triple-negative and HER2-positive early breast cancer (GeparSixto; GBG 66): a randomised phase 2 trial. The Lancet Oncology. 2014;15(7):747-56.

27. Sikov WM, Berry DA, Perou CM, Singh B, Cirrincione CT, Tolaney SM, Kuzma CS, Pluard TJ, Somlo G, Port ER, et al. Impact of the addition of carboplatin and/or bevacizumab to neoadjuvant once-perweek paclitaxel followed by dose-dense doxorubicin and cyclophosphamide on pathologic complete response rates in stage II to III triple-negative breast cancer: CALGB 40603 (Alliance). J Clin Oncol. 2015;33(1):13-21.

28. Abkevich V, Timms KM, Hennessy BT, Potter J, Carey MS, Meyer LA, Smith-McCune K, Broaddus R, Lu $\mathrm{KH}$, Chen J, et al. Patterns of genomic loss of heterozygosity predict homologous recombination repair defects in epithelial ovarian cancer. British journal of cancer. 2012;107(10):1776-82.

29. Birkbak NJ, Wang ZC, Kim JY, Eklund AC, Li Q, Tian R, Bowman-Colin C, Li Y, Greene-Colozzi A, Iglehart JD, et al. Telomeric allelic imbalance indicates defective DNA repair and sensitivity to DNAdamaging agents. Cancer Discov. 2012;2(4):366-75.

30. Popova T, Manié E, Rieunier G, Caux-Moncoutier V, Tirapo C, Dubois T, Delattre O, Sigal-Zafrani B, Bollet $\mathrm{M}$, Longy $\mathrm{M}$, et al. Ploidy and large-scale genomic instability consistently identify basal-like breast carcinomas with BRCA1/2 inactivation. Cancer Res. 2012;72(21):5454-62.

31. Timms KM, Abkevich V, Hughes E, Neff C, Reid J, Morris B, Kalva S, Potter J, Tran TV, Chen J, et al. Association of BRCA1/2 defects with genomic scores predictive of DNA damage repair deficiency among breast cancer subtypes. Breast Cancer Res. 2014;16(6):475.

32. Marquard AM, Eklund AC, Joshi T, Krzystanek M, Favero F, Wang ZC, Richardson AL, Silver DP, Szallasi Z, Birkbak NJ. Pan-cancer analysis of genomic scar signatures associated with homologous recombination deficiency suggests novel indications for existing cancer drugs. Biomarker research. 2015;3:9.

33. Loibl S, Weber KE, Timms KM, Elkin EP, Hahnen E, Fasching PA, Lederer B, Denkert C, Schneeweiss A, Braun S, et al. Survival analysis of carboplatin added to an anthracycline/taxane-based neoadjuvant chemotherapy and HRD score as predictor of response-final results from GeparSixto. Ann Oncol. 2018;29(12):2341-7.

34. Telli ML, Timms KM, Reid J, Hennessy B, Mills GB, Jensen KC, Szallasi Z, Barry WT, Winer EP, Tung NM, et al. Homologous Recombination Deficiency (HRD) Score Predicts Response to PlatinumContaining Neoadjuvant Chemotherapy in Patients with Triple-Negative Breast Cancer. Clin Cancer Res. 2016;22(15):3764-73. 
35. Telli ML, Metzger O, Timms K, Evans B, Vogel D, Wei H, Jones JT, Wenstrup RJ, McKee MD, Sullivan $\mathrm{DM}$, et al: Evaluation of homologous recombination deficiency (HRD) status with pathological response to carboplatin $+/$ - veliparib in BrighTNess, a randomized phase 3 study in early stage TNBC. 2018, 36(15_suppl):519-519.

36. Tutt A, Tovey H, Cheang MCU, Kernaghan S, Kilburn L, Gazinska P, Owen J, Abraham J, Barrett S, Barrett-Lee P, et al. Carboplatin in BRCA1/2-mutated and triple-negative breast cancer BRCAness subgroups: the TNT Trial. Nature medicine. 2018;24(5):628-37.

37. Yerushalmi R, Woods R, Ravdin PM, Hayes MM, Gelmon KA. Ki67 in breast cancer: prognostic and predictive potential. The Lancet Oncology. 2010;11(2):174-83.

38. Andre F, Arnedos M, Goubar A, Ghouadni A, Delaloge S. Ki67-no evidence for its use in node-positive breast cancer. Nat Rev Clin Oncol. 2015;12(5):296-301.

39. Munzone E, Botteri E, Sciandivasci A, Curigliano G, Nole F, Mastropasqua M, Rotmensz N, Colleoni M, Esposito A, Adamoli L, et al. Prognostic value of $\mathrm{Ki}-67$ labeling index in patients with node-negative, triple-negative breast cancer. Breast Cancer Res Treat. 2012;134(1):277-82.

40. Zhu X, Chen L, Huang B, Wang Y, Ji L, Wu J, Di G, Liu G, Yu K, Shao Z, et al. The prognostic and predictive potential of Ki-67 in triple-negative breast cancer. Sci Rep. 2020;10(1):225.

41. Wang W, Wu J, Zhang P, Fei X, Zong Y, Chen X, Huang O, He JR, Chen W, Li Y, et al. Prognostic and predictive value of Ki-67 in triple-negative breast cancer. Oncotarget. 2016;7(21):31079-87.

42. Nik-Zainal S, Davies H, Staaf J, Ramakrishna M, Glodzik D, Zou X, Martincorena I, Alexandrov LB, Martin S, Wedge DC, et al. Landscape of somatic mutations in 560 breast cancer whole-genome sequences. Nature. 2016;534(7605):47-54.

\section{Figures}




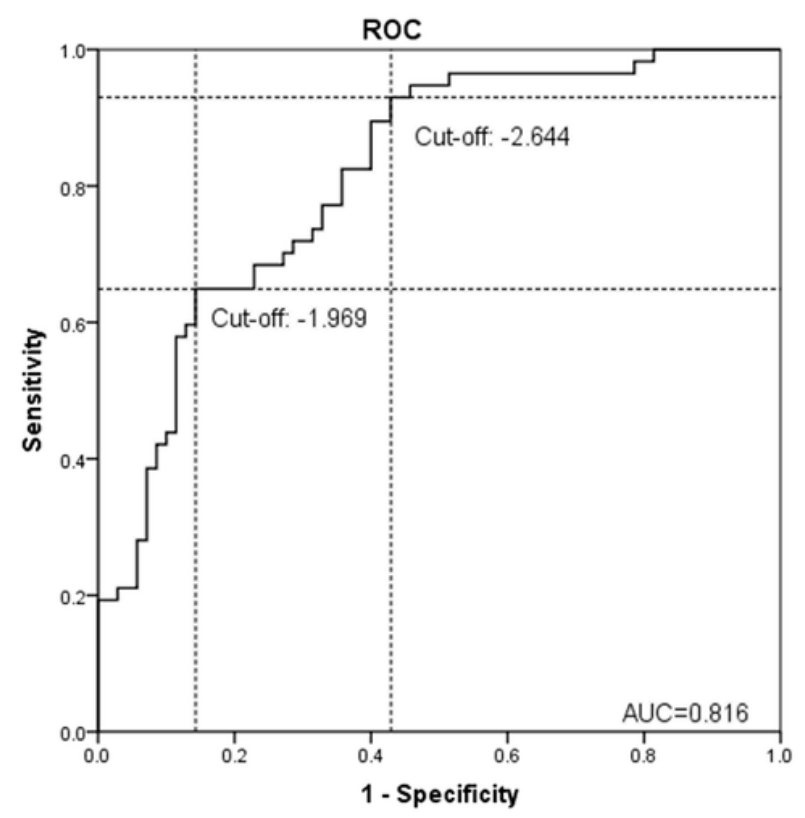

A. The ROC curve for $\mathrm{pCR}$ in breast

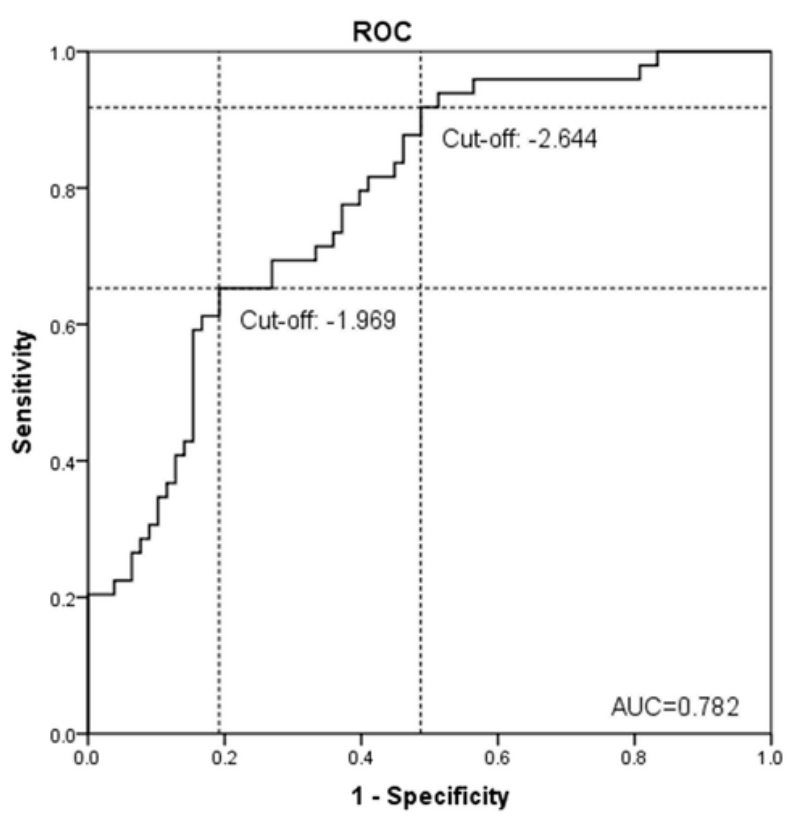

B. The ROC curve for $p C R$ in breast/axilla

\section{Figure 1}

ROC curve analysis for pCR in breast and pCR in breast/axilla . ROC curve analysis yielded an area under the curve (AUC) of 0.816 and 0.782 for $p C R$ in breast (A) and pCR in breast/axilla (B) respectively.

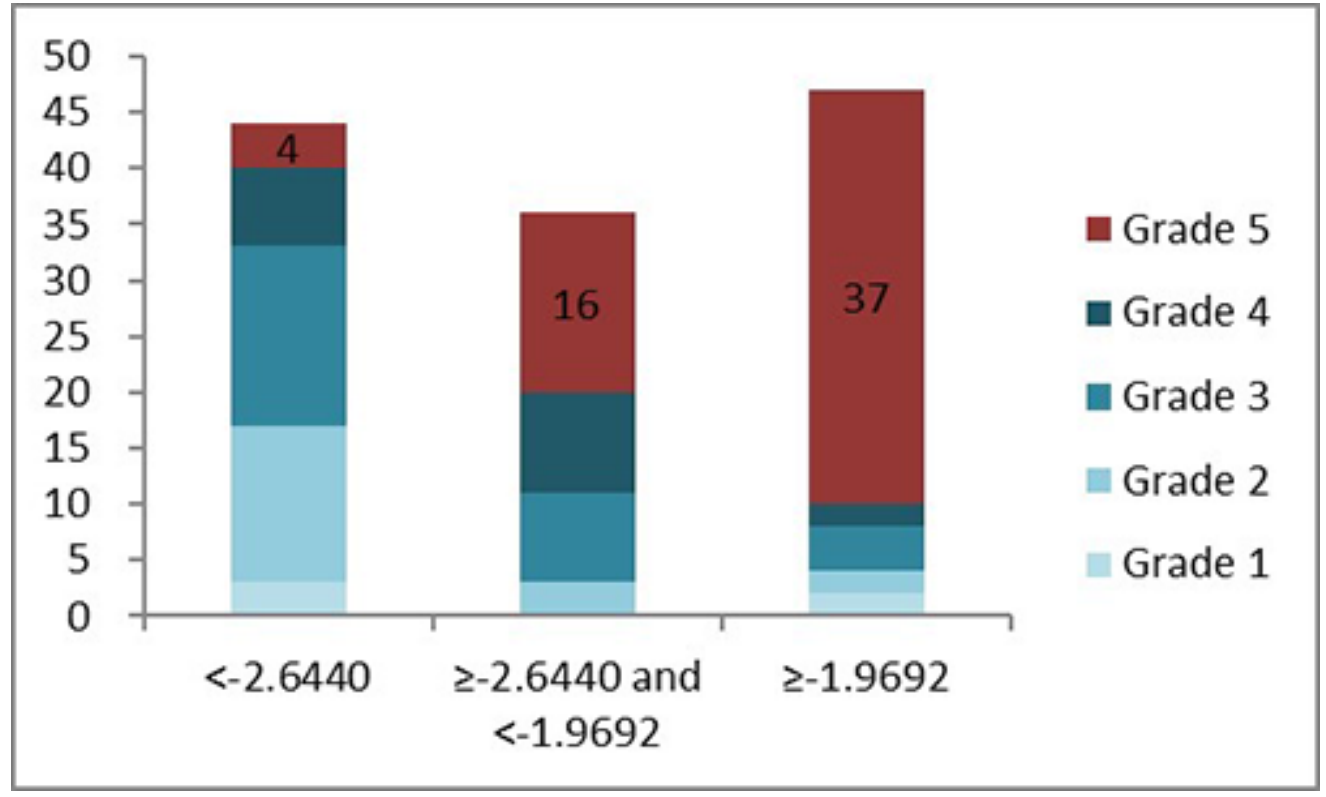

Figure 2

The distributions of patients with different Miller-Payne grading in three subgroups.

\section{Supplementary Files}


This is a list of supplementary files associated with this preprint. Click to download.

- TableS1.pdf

- Tables2.pdf

- TableS3.pdf

- TableS4.pdf 